\title{
Ethical Principles in a Time of Covid19- A Commentary
}

\section{Hoffman DP*}

Department of Ethics and Health Policy, Maria College, USA

*Corresponding author: David P Hoffman, Associate Dean for Academic Initiatives and Government Affairs, Department of Ethics and Health Policy, Maria College 700 New Scotland Ave, Albany, New York 12208, USA, Tel: 5183667544; Email: dhoffman@mariacollege.edu

\section{Commentary}

Volume 3 Issue 3

Received Date: August 01, 2020

Published Date: August 06, 2020

DOI: $10.23880 /$ abca-16000126

\section{Commentary}

A Texas hospital reports their back is against the wall and they may be sending some patients home to die. Hospitals in many areas report staffing shortages due to the pandemic. Many other providers report stressed out workers, patients and family members. I reviewed several lay press pieces regarding the pandemic in the past few days, conspicuous by its absence was any mention of the four principles of medical ethics first outlined in 1985 by Beauchamp and Childress. These thoughtful philosophers saw an opportunity in the wake of ethical horror stories like the Tuskegee Syphilis Experiments and the work of the Nazis under Josef Mengele (just as examples) to outline concepts we should all regard as primary in our approach to others-especially in the provision of healthcare and the conduct of research. The principled approach calls on us all to focus on a balance of four basic concepts beginning with the individual and wrapping up with society in general.

Briefly these concepts are first respect for autonomy-the concept that each of us has a right to make informed decisions about our own body and health. This right is most respected when these decisions are fully informed and not in any way coerced. The second and third concepts are beneficence (to do as much good as you can) and non-maleficence (the famous "first-do-no-harm"). The balance of these two recognizes that rarely are these perfectly balanced but awareness (being fully informed), mutual respect and understanding one another helps us achieve both in our interactions with others and healthcare systems. I say balance because some of the most effective healthcare interventions may extend life but have a negative impact on quality (i.e. antibiotics may kill an infection and also damage digestive systems and other bodily function). Lastly the principle of justice, that ideal of fairness that each of us have equal access to sometimes limited resources. Beauchamp and Childress pointed out in each iteration of their work on principles of ethics that justice is applied reflecting the prevailing philosophical theories of the place and time. This could call for resources to be expended based on those in highest need (like emergency triage) or based on who has most responsibility (a parent may receive care before a single adult) or based on the ability to pay. You can see that in each case there is immediately an argument over why this one or another philosophy should prevail.

My point today isn't that one definition of justice is better than others, or that one of these four principles should be a higher priority. These debates have occurred before and will be repeated throughout our imperfect history. My point today is that in each lay article I've read about the Covid19 Pandemic these principles are absent, indicating that the hard decisions of who receives limited care, who goes home to die, whether people receive appropriate palliative care are all secondary to the urgency of "fighting Covid19". I argue that the opposite is true, especially in these times we need to focus more on key principles of ethics related to our health. These are what assure we are our best selves, the best providers we can be, and the best societies we can become. I challenge my fellow educators, providers and ethicists to assure that in any public dialogue regarding the difficult decisions facing societies and individuals in this and future pandemics the concepts of autonomy, beneficence, nonmaleficence, and justice are prominent in private and public dialogue. It is essential for our future.

\section{References}

1. Tom LB, Childress JF (2013) Principles of Biomedical Ethics, $7^{\text {th }}$ (Edn.), Oxford University Press, pp: 499.

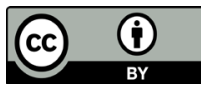

